\section{Human rights and clinical ethics are the right framework to address the probable DMPA-HIV interaction}

We were delighted to read the very timely paper by Haddad et al. ${ }^{1}$ that has become even more topical with the recent publication of a systematic review showing that depot medroxyprogesterone acetate (DMPA) use is indeed associated with about a $40 \%$ increased risk of HIV acquisition (12 studies involving more than 39500 women, pooled hazard ratio $1.40,95 \%$ confidence interval 1.16-1.69). ${ }^{2}$ Other forms of hormonal contraception do not appear to increase this risk. In the accompanying press release the lead author, Lauren Ralph, stated: "Banning DMPA would leave many women without immediate access to alternative, effective contraceptive options. This is likely to lead to more unintended pregnancies, and because childbirth remains life-threatening in many developing countries, could increase overall deaths among women". ${ }^{3}$ Globally over 40 million women use injectable contraception and as providers we need an appropriate framework to advise them. Two such frameworks are available, based on human rights and on clinical ethics, rather than on the public health principles suggested by Haddad et al. ${ }^{1}$

Reproductive freedom is recognised as a fundamental human right. It includes the right to access good quality information and services, free from coercion and discrimination. The United Nations Population Fund's 2010 briefing paper states that "governments should refrain from restricting women's ability to make free and informed choices, for example by strictly regulating or prohibiting a particular contraceptive method". ${ }^{4}$ The 2014 World Health Organization guidance places no medical eligibility criteria restriction on the provision of progestogen-only injectables and states: "Women at high risk of HIV infection should be informed that progestogenonly injectables may or may not increase their risk of HIV acquisition. Women and couples at high risk of HIV acquisition considering progestogen-only injectables should also be informed about and have access to HIV preventive measures, including male and female condoms". 5 At high policy level there is no hint of "you cannot have HIV prevention and contraception at the same time". Instead of creating policy conflicts we should be focusing on how best to integrate sexual and reproductive health services and HIV care in resource-poor areas such as sub-Saharan Africa. This is particularly important because it is largely the same underlying cultural and social issues that make it difficult for women to access both types of service. The impetus for integrating services is supported by international health policies and donor guidance. $^{6}$

Contraception is primarily a clinical intervention that also has significant public health gains. A commonly used clinical ethics framework has been described by Beauchamp and Childress: autonomy, non-maleficence, beneficence and justice (meaning a just use of resources). ${ }^{7}$ It is better equipped to protect the realisation of women's full enjoyment and participation of their sexual and reproductive human rights and to promote their empowerment (autonomy). To adhere to the principle of nonmaleficence ('first do no harm') we need to inform patients of possible risk (the probable $40 \%$ increased risk of HIV infection for women on DMPA). For patients to realise their right to full participation, they must be given the opportunity to understand the pros and cons of a specific contraceptive method. The principle of beneficence has been explained above by Lauren Ralph. ${ }^{3}$ Contraception is a highly cost-effective intervention to improve the health of women and children and thus a just use of resources.

In our view, a human rights framework realised through clinical ethics is a more appropriate approach to addressing the ethical challenges presented by Haddad et al., ${ }^{1}$ ultimately ensuring that women participate fully in the decisionmaking process, to realise their fundamental sexual and reproductive rights.

\section{Elana Covshoff, MA}

Health Improvement Practitioner, Guys and St Thomas' Foundation Trust - Community Services, London, UK; elanacovshoff@gmail.com

\section{Ulrike Sauer, MFSRH}

Consultant in Sexual and Reproductive Health, Margaret Pyke Centre, Reproductive Health, London, UK; ulrike.sauer@nhs.net

\section{Rudiger Pittrof, ${ }^{*} \mathrm{MSC}$}

Consultant in Community Sexual Health and HIV, GSTT - Sexual Health, St Thomas' Hospital, London, UK; Rudiger.Pittrof@gstt.nhs.uk
${ }^{*}$ Corresponding author.

Competing interests None.

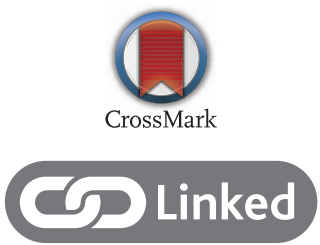

http://dx.doi.org/10.1136/jfprhc-2015-101204

J Fam Plann Reprod Health Care 2015;41:156. doi:10.1136/jprhc-2015-101176

\section{REFERENCES}

1 Haddad LB, Philpott-Jones S, Schonfeld T. Contraception and prevention of HIV transmission: a potential conflict of public health principles. J Fam Plann Reprod Health Care 2015;41:20-23.

2 Ralph LJ, McCoy S, Shiu K, et al. Hormonal contraceptive use and women's risk of HIV acquisition: a meta-analysis of observational studies. Lancet Infect Dis 2015;2:181-189.

3 EurekAlert! The Lancet Infectious Diseases: Study supports link between injectable hormonal contraceptive and HIV risk. News release: 8 January 2015. http://www. eurekalert.org/pub_releases/2015-01/ tl-tli010715.php [accessed 9 January 2015].

4 Centre for Human Rights, United Nations Population Fund (UNFPA). The Right to Contraceptive Information and Services for Women and Adolescents. 2010. http://www. unfpa.org/sites/default/files/resource-pdf/ Contraception.pdf [accessed 9 January 2015].

5 World Health Organization. Hormonal Contraceptive Methods for Women at High Risk of HIV and Living with HIV. 2014. http:/ apps.who.int/iris/bitstream/10665/128537/1/ WHO_RHR_14.24_eng.pdf?ua=1 [accessed 9 January 2015].

6 Hope R, Kendall T, Langer A, et al. Health systems integration of sexual and reproductive health and HIV services in sub-Saharan Africa: a scoping study. J Acquir Immune Defic Syndr 2014;67(Suppl. 4):S259-S270.

7 Beauchamp TL, Childress JF. Principles of Biomedical Ethics (7th edn). Oxford, UK: Oxford University Press, 2013. 